\title{
Low Temperature CVD of Thin, Amorphous Boron-Carbon Films for Neutron Detectors
}

\author{
Henrik Pedersen, Carina Höglund, Jens Birch, Jens Jensen and Anne Henry
}

\section{Linköping University Post Print}

N.B.: When citing this work, cite the original article.

This is the authors' version of the original publication:

Henrik Pedersen, Carina Höglund, Jens Birch, Jens Jensen and Anne Henry, Low Temperature CVD of Thin, Amorphous Boron-Carbon Films for Neutron Detectors, 2012, Chemical Vapor Deposition, (18), 7-9, 221-224.

http://dx.doi.org/10.1002/cvde.201206980

Copyright: Wiley-VCH Verlag Berlin http://www.wiley-vch.de/publish/en/

Postprint available at: Linköping University Electronic Press http://urn.kb.se/resolve?urn=urn:nbn:se:liu:diva-84903 


\title{
Low temperature chemical vapor deposition of thin, amorphous boron-carbon films for neutron detectors
}

\author{
Dr. Henrik Pedersen ${ }^{a, *}$, Dr. Carina Höglund ${ }^{a, b}$, Prof. Jens Birch ${ }^{a}$, Dr. Jens Jensen ${ }^{a}$, Prof. \\ Anne Henry ${ }^{\text {a }}$ \\ a Department of Physics, Chemistry and Biology \\ Linköping University \\ SE-581 83 Linköping, Sweden \\ ${ }^{\mathrm{b}}$ European Spallation Source ESS AB \\ P.O Box 176 \\ SE-221 00 Lund, Sweden
}

*Corresponding author; e-mail: henke@ifm.liu.se 


\title{
Keywords:
}

Low temperature CVD; boron-carbon films; organoborane; Elastic Recoil Detection Analysis (ERDA); neutron detection

\begin{abstract}
:
Thin, amorphous boron-carbon films were deposited at low temperature $\left(400-600{ }^{\circ} \mathrm{C}\right)$ by thermally activated CVD using the organoborane triethylboron (TEB) as a single precursor. Two different carrier gases were tested. At $600^{\circ} \mathrm{C}$ using argon as carrier gas the deposition rate was close to $1 \mu \mathrm{m} / \mathrm{h}$. The film had a density of $2.14 \mathrm{~g} / \mathrm{cm}^{3}$ with a $\mathrm{B} / \mathrm{C}$-ratio of 3.7. When hydrogen was used as carrier gas the film density was $2.42 \mathrm{~g} / \mathrm{cm}^{3}$, the $B / C$ ratio 4.6 and the deposition rate $0.35 \mu \mathrm{m} / \mathrm{h}$. The hydrogen content in the films was about 3-4 at\%, regardless of deposition ambient and varied only with the deposition temperature. In addition, both the film composition and the film density were found to vary significantly with the deposition temperature and the deposition ambient. Based upon these results, a deposition mechanism for the growth of boroncarbon films from TEB, where the TEB molecule is decomposed to $\mathrm{BH}_{3}$ and hydrocarbons, is suggested.
\end{abstract}

\section{Introduction}

The increased demand for ${ }^{3} \mathrm{He}$ and the upcoming ${ }^{3} \mathrm{He}$ shortage crisis have lead to unaffordable prices and an urgent need for a new generation of neutron detectors based on other elements. ${ }^{[1]}$ The boron isotope ${ }^{10} \mathrm{~B}$ (naturally occurring boron contains 
20 at $\%$ of ${ }^{10} \mathrm{~B}, 80$ at $\%$ being ${ }^{11} \mathrm{~B}$ ) has one of the highest neutron absorption cross sections for thermal neutrons and is thus a highly promising element for neutron detectors. Boron carbides $\left(\mathrm{B}_{\mathrm{x}} \mathrm{C}\right)$ are well known to have excellent wear resistance, thermal and chemical stability. ${ }^{[2]}$ They are stable even with very high $\mathrm{B} / \mathrm{C}$-ratios, as high as $50,{ }^{[3]}$ and, therefore, among the most interesting materials to be used for neutron detectors. Recently Höglund et al. ${ }^{[4]}$ demonstrated that thin films of ${ }^{10} \mathrm{~B}_{4} \mathrm{C}$, synthesized by sputter deposition, are very promising in the next generation of large scale neutron detectors. A preferred design of neutron detectors contains blades that are made of $\mathrm{Al}$, which is a material that can easily be machined, is inexpensive, and is close to neutron transparent. The blades are coated with $\sim 1 \mu \mathrm{m}$ thick layer of ${ }^{10} \mathrm{~B}_{4} \mathrm{C}$. During neutron irradiation, the ${ }^{10} \mathrm{~B}$ absorbs the neutron by the nuclear reaction:

$$
{ }^{10} \mathrm{~B}+\mathrm{n} \rightarrow{ }^{7} \mathrm{Li}+{ }^{4} \mathrm{He}+2.3 \mathrm{MeV}
$$

Both the ${ }^{7} \mathrm{Li}$ and ${ }^{4} \mathrm{He}$ isotopes can be detected, with both temporal and spatial resolutions in a detecting gas.

One of the critical issues with $B_{x} C$ thin films for neutron detectors is to minimize the amount of impurities which otherwise disturb the neutron detection by scattering the products of reaction (1). Especially hydrogen and heavier elements like oxygen and nitrogen scatter neutrons making the neutron detection less precise. Therefore the amount of ${ }^{10} \mathrm{~B}$ has to be maximized, while the amount of impurities must be minimized. The films also need to have good adhesion to the substrate for thicknesses in the range 
of $1 \mu \mathrm{m}$, which often is seen as an issue due to the high residual stresses frequently observed in boron carbide thin films. ${ }^{[5]}$ However, the application as neutron detector puts no demands on the crystallinity of the films.

As for many other technical thin films, one can use either CVD or PVD techniques to deposit $B_{x} C$ films. The main advantage of PVD is the low process temperature and low hydrogen contamination of the films (provided that a low background pressure is obtained in the deposition chamber and that a hydrogen-free target and high purity process gases are used). However the PVD technique suffers from the drawback of lineof-sight deposition. Hence great advantages can be achieved by using a CVD process which gives the possibility to coat substrates of complex shapes over very large areas. In most reports on boron-carbon films deposition using CVD, boron chloride $\left(\mathrm{BCl}_{3}\right)$ and some hydrocarbon, typically methane $\left(\mathrm{CH}_{4}\right)$, are used as precursors at process temperatures of $900-1300{ }^{\circ} \mathrm{C} \cdot{ }^{[6,7,8,9,10,11]}$ The use of a chlorinated chemistry produces a very corrosive environment in the reactor which is detrimental for most metallic substrates, such as aluminum. Moreover, Al has a relatively low melting point of $660{ }^{\circ} \mathrm{C}$. Therefore, alternative chemistries and precursors must be identified for low temperature CVD growth of $\mathrm{B}_{\mathrm{x}} \mathrm{C}$ on aluminum substrates. A promising route would be to use organoborane molecules which would be able to act as both carbon and boron precursor and make for a single-precursor process for $\mathrm{B}_{\mathrm{x}} \mathrm{C}$. Thermally activated CVD of $\mathrm{B}_{\mathrm{x}} \mathrm{C}$ from organoboranes has been demonstrated; triethylborane or TEB $\left(B\left(\mathrm{C}_{2} \mathrm{H}_{5}\right)_{3}\right)$ was preferred over trimethylborane $\left(\mathrm{B}\left(\mathrm{CH}_{3}\right)_{3}\right)$, which was found to be over-reactive, and tributylborane $\left(B\left(\mathrm{C}_{4} \mathrm{H}_{9}\right)_{3}\right)$, which was found to very 
erratic reactions. ${ }^{[12]}$ The films were deposited at $400-1100{ }^{\circ} \mathrm{C}$, at low pressure $(9-27$ mbar) or atmospheric pressure, in hydrogen or argon ambient and were found to be carbon rich, with $\mathrm{B} / \mathrm{C}$ ratios around 0.5 , except for depositions in hydrogen at low pressure, temperature and precursor concentrations when $\mathrm{B} / \mathrm{C}$ ratios around 1.5 was obtained. Recently the deposition of $\mathrm{B}_{\mathrm{x}} \mathrm{C}$ films by Hot Filament CVD (HFCVD) from orthocarborane $\left(\mathrm{o}-\mathrm{C}_{2} \mathrm{~B}_{10} \mathrm{H}_{12}\right)$ in argon carrier gas has been reported. ${ }^{[13]}$ The films deposited with a filament temperature of $1500-2000^{\circ} \mathrm{C}$ and at a substrate temperature of 200 $300{ }^{\circ} \mathrm{C}$ were reported to be a crystalline mixture of $\mathrm{B}_{4} \mathrm{C}, \mathrm{B}_{13} \mathrm{C}_{2}$ and $\mathrm{B}_{25} \mathrm{C}$ with a hydrogen content of around 20 at\%.

This paper presents a study of low temperature $\left(400-600^{\circ} \mathrm{C}\right) \mathrm{CVD}$ of boron-carbon films from triethylborane (TEB). Two different carrier gases are tested: hydrogen and argon. The deposition rate, density and composition of the films are investigated. Based upon our results, a decomposition mechanism of the single precursor (TEB) for the deposition of boron-carbon films is discussed.

\section{Results}

The deposited boron-carbon films have a pale gray color when deposited on aluminum and a shinier gray appearance when deposited on Si-substrates. They are XRDamorphous, and appear very dense in cross sectional SEM (Figure 1), regardless of deposition ambient and temperature. Films with a thickness of $0.5-1 \mu \mathrm{m}$ adhere well to both aluminum and silicon substrate. The densities of the films are summarized in Table 1. The film deposited at $600^{\circ} \mathrm{C}$ with hydrogen as carrier gas has a density very 
close to that reported for bulk $\mathrm{B}_{4} \mathrm{C}\left(2.52 \mathrm{~g} / \mathrm{cm}^{3}\right),{ }^{[2]}$ while the film deposited at the same temperature with argon ambient has a lower density. Further, the densities are found to be strongly dependent on the deposition temperature.

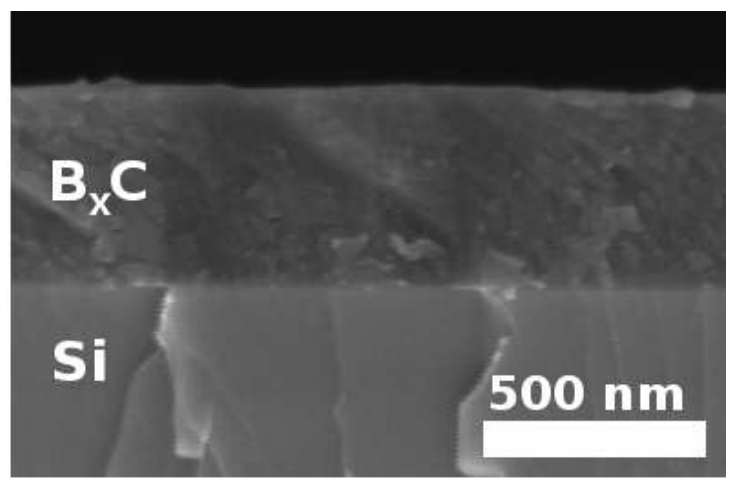

Figure 1: Cross sectional SEM micrograph of a $\mathrm{B}_{\mathrm{x}} \mathrm{C}$ film deposited on a silicon substrate at $600^{\circ} \mathrm{C}$ in $\mathrm{Ar}$ ambient.

Table 1: Summary of film densities as measured by XRR for various films deposited on silicon substrates using different carrier gas $\left(\mathrm{H}_{2}\right.$ or $\left.\mathrm{Ar}\right)$ and different growth temperatures.

\begin{tabular}{ccc}
\hline Carrier gas & Deposition temperature $\left({ }^{\circ} \mathrm{C}\right)$ & Density $\left(\mathrm{g} / \mathrm{cm}^{\mathbf{3}}\right)$ \\
\hline $\mathrm{H}_{2}$ & 400 & $1.16 \pm 0.3$ \\
$\mathrm{H}_{2}$ & 600 & $2.42 \pm 0.05$ \\
$\mathrm{Ar}$ & 500 & $1.85 \pm 0.05$ \\
$\mathrm{Ar}$ & 600 & $2.14 \pm 0.05$ \\
\hline
\end{tabular}


The deposition rates of the films were also found to be highly dependent of the deposition atmosphere, i.e. carrier gas, as well as the deposition temperature. The deposition rate at $600{ }^{\circ} \mathrm{C}$ was found to be $350 \mathrm{~nm} / \mathrm{h}$ in hydrogen and $960 \mathrm{~nm} / \mathrm{h}$ in argon atmosphere, respectively. The deposition rate in argon dropped to $410 \mathrm{~nm} / \mathrm{h}$ when the deposition temperature was lowered to $500^{\circ} \mathrm{C}$.

Table 2: Summary of elemental composition in the boron-carbon films deposited on both silicon and aluminum substrates as determined by ToF-ERDA. The experimental uncertainties for these measurements are 1-1.5 at\%.

\begin{tabular}{|c|c|c|c|c|c|c|}
\hline \multirow[b]{2}{*}{ Carrier gas } & \multicolumn{2}{|l|}{ Deposition } & \multirow[b]{2}{*}{ B (at\%) } & \multirow[b]{2}{*}{ C (at\%) } & \multirow[b]{2}{*}{ H (at\%) } & \multirow[b]{2}{*}{$\mathrm{O}$ (at\%) } \\
\hline & Temperature $\left({ }^{\circ} \mathrm{C}\right)$ & $\mathrm{B} / \mathrm{C}$ & & & & \\
\hline $\mathrm{H}_{2}$ & 400 & 23.7 & 71 & 3 & 25 & 1 \\
\hline $\mathrm{H}_{2}$ & 500 & 13.1 & 78.5 & 6 & 15 & 0.5 \\
\hline $\mathrm{H}_{2}$ & 600 & 4.6 & 79 & 17 & 3.9 & 0.1 \\
\hline $\mathrm{Ar}$ & 400 & 2.9 & 56 & 19.5 & 24 & 0.5 \\
\hline $\mathrm{Ar}$ & 500 & 3.5 & 66 & 19 & 14.5 & 0.5 \\
\hline $\mathrm{Ar}$ & 600 & 3.7 & 75.5 & 20.5 & 3.9 & 0.1 \\
\hline
\end{tabular}

The elemental composition of the films is summarized in Table 2. Boron is the prominent element for all the deposited films with a boron content in the range of 7080 at\% for the films deposited with hydrogen, and slightly lower (55-75 at\%) for the films deposited in argon atmosphere. In both hydrogen and argon ambient the boron content is found to increase with increasing deposition temperature, although the effect 
is more pronounced in argon ambient. The carbon content in the films shows very different behavior for the two different deposition atmospheres. For films deposited in hydrogen, the carbon content is increasing from 3 at\% to 17 at $\%$ when the deposition temperature is increased from 400 to $600^{\circ} \mathrm{C}$, while an argon ambient results in films with a carbon content of around 20 at\%, regardless of the deposition temperature. It is interesting to note that the hydrogen content is independent of the deposition ambient, whereas the deposition temperature has a strong effect on the hydrogen content in the films; the hydrogen content is decreased from 25 to 4 at\% when the temperature is increased from 400 to $600{ }^{\circ} \mathrm{C}$. The oxygen content in the deposited films is very low (0.51 at\%), regardless of the deposition ambient and temperature.

\section{Discussion}

In the previous study on CVD of $B_{x} C$ films from TEB, ${ }^{[12]}$ it was pointed out that TEB undergoes $\beta$-elimination where a hydrogen atom from an ethyl group bonds to the boron atom and the ethyl group leaves as ethylene:

$$
\mathrm{B}\left(\mathrm{C}_{2} \mathrm{H}_{5}\right)_{3} \rightarrow \mathrm{B}\left(\mathrm{C}_{2} \mathrm{H}_{5}\right)_{2} \mathrm{H}+\mathrm{C}_{2} \mathrm{H}_{4}
$$

This reaction was reported to occur at $300{ }^{\circ} \mathrm{C}$, and it is thus expected that at higher temperatures than $300{ }^{\circ} \mathrm{C}$, the other two ethyl groups could also be eliminated to form $\mathrm{BH}_{3}$, as: 


$$
\mathrm{B}\left(\mathrm{C}_{2} \mathrm{H}_{5}\right)_{2} \mathrm{H} \rightarrow \mathrm{BH}_{3}+2 \mathrm{C}_{2} \mathrm{H}_{4}
$$

In this way, the TEB molecule will act very similar to the diborane $\left(\mathrm{B}_{2} \mathrm{H}_{6}\right)$ molecule which is reported to decompose to $\mathrm{BH}_{3}$ in the gas phase. In this case, $\mathrm{BH}_{3}$ is the active boron containing specie for the deposition of $B_{x} C$ films. ${ }^{[14,15]}$ It is reasonable to assume that the elimination of ethyl groups from the TEB molecule is temperature dependent, and thus at higher temperatures more $\mathrm{BH}_{3}$ is formed. The observed increase in boron content at higher deposition temperature in argon can be explained by an increasing degree of TEB decomposition and hence a higher $\mathrm{BH}_{3}$ formation.

However, the high boron content obtained in hydrogen ambient, almost regardless of deposition temperature, suggests that the formation of $\mathrm{BH}_{3}$ by decomposition of TEB is more effective and/or less temperature dependent in hydrogen ambient compared to argon ambient. An explanation could be that hydrogen molecules take part in the elimination of the ethyl groups and thus open up new reaction pathways, other than $\beta$ elimination, for the formation of $\mathrm{BH}_{3}$ from TEB. Upon the formation of $\mathrm{BH}_{3}$ from TEB, the three ethyl groups in TEB should mainly form ethylene $\left(\mathrm{C}_{2} \mathrm{H}_{4}\right)$ by $\beta$-elimination from TEB. However, if speculated that the hydrogen ambient could assist in the TEB decomposition, the ethyl groups should form ethane $\left(\mathrm{C}_{2} \mathrm{H}_{6}\right)$ together with hydrogen according to:

$$
\mathrm{B}\left(\mathrm{C}_{2} \mathrm{H}_{5}\right)_{3}+\mathrm{H}_{2} \rightarrow \mathrm{B}\left(\mathrm{C}_{2} \mathrm{H}_{5}\right)_{2} \mathrm{H}+\mathrm{C}_{2} \mathrm{H}_{6}
$$


This should mean that in hydrogen ambient at low temperature $\mathrm{C}_{2} \mathrm{H}_{6}$ is mainly formed in the reactor. The $\mathrm{C}_{2} \mathrm{H}_{6}$ molecule is reported to decompose to two methyl radicals $\left({ }^{*} \mathrm{CH}_{3}\right)$ ${ }^{[16,17]}$ which would then likely form methane $\left(\mathrm{CH}_{4}\right)$ together with the hydrogen carrier gas. For the deposition at higher temperatures and with hydrogen ambient, ethylene is mainly formed through $\beta$-elimination, which is more reactive than methane and thus the films are deposited with higher carbon content. For the deposition in argon atmosphere, the formation of $\mathrm{C}_{2} \mathrm{H}_{6}$ according to (4) is not possible and the TEB molecule is forced to decompose via $\beta$-elimination. Thus reactive ethylene is the dominating carbon molecule in argon, regardless the temperature, which would explain why the carbon content in the films deposited in argon is independent of the deposition temperature.

The higher densities for the films deposited at higher temperatures are consistent with the lower hydrogen content. A lower hydrogen content at higher deposition temperatures is attributed to easier out-diffusion of hydrogen from the films. Moreover it can be speculated that the surface chemistry for the removal of hydrogen from adsorbed $\mathrm{BH}_{\mathrm{x}}$ and hydrocarbons is more efficient at higher deposition temperatures, leading to less incorporation of hydrogen in these films.

It is interesting to note that even though the B/C-ratios for films deposited in argon at $600{ }^{\circ} \mathrm{C}$ is 3.62 and at $500^{\circ} \mathrm{C}$ is 3.54 ; the films significantly differ in their hydrogen content, 3.7 and 14.6 at\%, respectively. The hydrogen content in the films is also reflected in the difference in densities between the films, with 2.14 and $1.85 \mathrm{~g} / \mathrm{cm}^{3}$ for deposition at 600 and $500{ }^{\circ} \mathrm{C}$, respectively. This is an indication for that lowering the 
deposition temperature from 600 to $500{ }^{\circ} \mathrm{C}$ results in the same boron carbide, by the same deposition chemistry, but that a higher temperature is needed to remove the hydrogen atoms (or molecules) from the films.

The more than doubled deposition rate at $600^{\circ} \mathrm{C}$ in argon ambient compared to hydrogen ambient, could be attributed to a significantly higher etching of the film in hydrogen ambient. The fact that the films are found to have the same composition, regardless of the ambient when deposited at $600{ }^{\circ} \mathrm{C}$, suggests that the deposition mechanisms are similar in both ambients, which further indicates that hydrogen etching is responsible for the lower growth rate. The lowering of the growth rate at a lower deposition temperature in argon could be explained by a less efficient chemistry for the formation of the boron species active for the growth.

\section{Conclusions}

This study shows that thin, amorphous boron-carbon films with $\mathrm{B}_{4} \mathrm{C}$ stoichiometry can be deposited at low process temperatures of $600^{\circ} \mathrm{C}$ using thermally activated CVD and the organoborane molecule triethylboron (TEB) as single precursor as opposed to the traditional boronhalide or diborane plus hydrocarbon route. Films with B/C-ratio of 4.6 and 3.6 were deposited at $600{ }^{\circ} \mathrm{C}$ in hydrogen and argon, respectively, with a low hydrogen content of 3-4 at\%. The film compositions and densities were found to vary significantly with the deposition temperatures and the deposition ambient; films deposited at $400^{\circ} \mathrm{C}$ and in hydrogen had a B/C-ratio of 25 while those deposited in argon had a B/C-ratio of 3 . The hydrogen content was found to be highly temperature 
dependent, most likely due to enhanced out diffusion of hydrogen at higher

temperatures. Prior studies of $\mathrm{B}_{\mathrm{x}} \mathrm{C}$ deposition at either significantly higher temperature of much lower pressure using organoboranes yielded mainly films rich in carbon with stoichiometries ranging from $\mathrm{B}_{0.5} \mathrm{C}$ to $\mathrm{B}_{1.5} \mathrm{C} .{ }^{[12]}$

Based upon these results, a deposition mechanism for boron-carbon films from TEB, where the TEB molecule is decomposed to $\mathrm{BH}_{3}$ and hydrocarbons, is suggested. It is proposed that the decomposition of TEB in hydrogen can give rise to both $\mathrm{C}_{2} \mathrm{H}_{4}$ and $\mathrm{C}_{2} \mathrm{H}_{6}$, while the decomposition in argon only yields to $\mathrm{C}_{2} \mathrm{H}_{4}$. Depending on which hydrocarbons are formed, the carbon chemistry in the deposition process is more or less efficient in supplying carbon to the growth, thus making the B-C stochiometries in the films highly dependent on the deposition ambient.

This work show, for the first time, that boron rich films (in particular $\mathrm{B}_{4} \mathrm{C}$ ) can be deposited by a simple CVD process at temperatures low enough to coat aluminum without damaging the substrates. As example, this is thus a promising route for making the next generation of neutron detectors.

\section{Experimental details}

A hot wall CVD reactor equipped with an inductively heated, $\mathrm{SiC}$ coated graphite susceptor was used for the deposition of the $\mathrm{B}_{\mathrm{x}} \mathrm{C}$ films. Further details on this type of CVD reactor have been described earlier. ${ }^{[18]}$ As carrier gas, palladium membrane purified hydrogen or argon (99.9997\%) was used, the process pressure was controlled by a throttle valve and set to 50 mbar. Triethyl boron, $B\left(\mathrm{C}_{2} \mathrm{H}_{5}\right)_{3}$ (TEB) was used as single 
precursor for the $\mathrm{B}_{\mathrm{x}} \mathrm{C}$ films, supplying both boron and carbon atoms to the process with a B/C-ratio of $1 / 6$. The TEB (SAFC Hitech) was of semiconductor grade purity and kept in a stainless steel bubbler immersed in a temperature controlled water/glycol bath to ensure a constant, well controlled temperature of $7{ }^{\circ} \mathrm{C}$ of the TEB which gives a TEB vapor pressure of 28.7 mbar. A small flow of the carrier gas, controlled by an electronic mass flow controller, was bubbled through the liquid; the pressure in the bubbler was controlled by an electronic pressure controller. The TEB concentration in the gas mixture in the reactor was $0.06 \%$. Single crystalline silicon wafers, (100)-oriented, and aluminum plates (type Al5083) approximately $1.5 \times 1.5 \mathrm{~cm}^{2}$, were used as substrates for the deposition. Prior to deposition, the substrates were cleaned in ultrasonic baths of Neutracon, a commercial cleaning product designed for cleaning of certain metals such as aluminum, followed by de-ionized water, or acetone followed by ethanol, for Al and $\mathrm{Si}$, respectively. The substrates were blown dry in dry $\mathrm{N}_{2}$. The thickness of the films deposited on Si-substrates was determined using scanning electron microscopy (SEM) on cleaved samples. The crystallinity of the films was studied by $x$-ray diffraction (XRD) in a Bragg-Brentano configuration. The density of the films was measured by X-ray Reflectivity (XRR) for the films deposited on Si substrate. Time of flight-energy elastic recoil detection analysis (ToF-E ERDA) was used to determine the elemental composition in the films.

\section{References}

[1] D. Kramer, Physics Today 2011, 64, 20. 
[2] O. Knotek, E. Lungscheider, C. W. Siry, Surf. Coat. Tech. 1997, 91, 167.

[3] K. Ploog, J. Cryst. Growth 1974, 24/25, 197.

[4] C. Höglund, J. Birch, K. Andersen, T. Bigault, J-C. Buffet, J. Correa, P. van Esch, B.

Guerard, R. Hall-Wilton, J. Jensen, A. Khaplanov, F. Piscitelli, C. Vettier, W. Vollenberg, L. Hultman, submitted.

[5] V. Kulikovsky, V. Vorlicek, P. Bohac, R. Ctvrtlik, M. Stranyanek, A. Dejneka, L. Jastrabik, Diam. Rel. Mat. 2009, 18, 27.

[6] U. Jansson, J-O. Carlsson, Thin Solid Films 1985, 124, 101.

[7] L. G. Vandenbulcke, Ind. Eng. Chem. Prod. Res. Dev. 1985, 24, 568.

[8] U. Jansson, J-O. Carlsson, B. Stridh, S. Söderberg, M. Olsson, Thin Solid Films 1989, $172,81$.

[9] H. Vincent, C. Vincent, M. P. Berthet, J. Bouix, G. Gonzalez, Carbon 1996, 34, 1041.

[10] J. Berjonneau, G. Chollon, F. Langlais, J. Electrochem. Soc. 2006, 153, C795.

[11] Y. Liu, L. Zhang, L. Cheng, Q. Zeng, W. Zhang, W. Yang, Z. Feng, B. Zeng, Appl. Surf. Sci. 2009, 255, 5729.

[12] J. S. Lewis, S. Vaidyaraman, W. J. Lackey, P. K. Agrawal, G. B. Freeman, E. K. Barefield, Mater. Lett. 1996, 27, 327.

[13] P. Chaudhari, N. Meshram, A. Singh, A. Topkar, R. Dusane, Thin Solid Films 2011, $519,4561$.

[14] T. P. Fehlner, S. A. Fridmann, Inorg. Chem. 1970, 9, 2288.

[15] D. A. Lamborn, D. W. Snyder, X. X. Xi, J. M. Redwing, J. Cryst. Growth 2007, 299, 358.

[16] G. M. Petrov, J. L. Giuliani, J. Appl. Phys. 2001, 90, 619. 
[17] W. Tsang, R. F. Hampson, J. Phys. Chem. Ref. Data 1986, 15, 1087.

[18] A. Henry, J. Hassan, J. P. Bergman, C. Hallin, E. Janzén, Chem. Vap. Deposition 2006, 12,475 . 